\title{
CXCR4-Specific Nanobodies as Potential Therapeutics for WHIM syndrome ${ }^{\text {[ }}$
}

\author{
Raymond $\mathrm{H}$. de Wit, Raimond Heukers, Hendrik J. Brink, Angela Arsova, ${ }^{1}$ \\ David Maussang, ${ }^{2}$ Pasquale Cutolo, Beatrijs Strubbe, Henry F. Vischer, \\ Françoise Bachelerie, and Martine J. Smit
}

Division of Medicinal Chemistry, Amsterdam Institute for Molecules, Medicines and Systems (AIMMS), Vrije Universiteit Amsterdam, Amsterdam, The Netherlands (R.H.d.W., R.H., H.J.B., A.A., D.M., H.F.V, M.J.S.); Inflammation Chemokines and Immunopathology, INSERM, Faculté de Médicine-Université Paris-Sud, Université Paris-Saclay, Clamart, France (P.C., F.B.); and Ablynx N.V., Zwijnaarde, Belgrium (B.S.)

Received May 14, 2017; accepted July 10, 2017

\begin{abstract}
WHIM syndrome is a rare congenital immunodeficiency disease, named after its main clinical manifestations: warts, hypogammaglobulinemia, infections, and myelokathexis, which refers to abnormal accumulation of mature neutrophils in the bone marrow. The disease is primarily caused by C-terminal truncation mutations of the chemokine receptor CXCR4, giving these CXCR4-WHIM mutants a gain of function in response to their ligand CXCL12. Considering the broad functions of CXCR4 in maintaining leukocyte homeostasis, patients are panleukopenic and display altered immune responses, likely as a consequence of impairment in the differentiation and trafficking of leukocytes. Treatment of WHIM patients currently consists of symptom relief, leading to unsatisfactory clinical responses. As an alternative and potentially more effective approach, we tested the potency and efficacy of CXCR4-specific nanobodies on inhibiting CXCR4-WHIM mutants. Nanobodies are therapeutic proteins based on the smallest functional fragments of heavy chain antibodies. They combine the advantages
\end{abstract}

of small-molecule drugs and antibody-based therapeutics due to their relative small size, high stability, and high affinity. We compared the potential of monovalent and bivalent CXCR4-specific nanobodies to inhibit CXCL12-induced CXCR4-WHIM-mediated signaling with the small-molecule clinical candidate AMD3100. The CXCR4targeting nanobodies displace CXCL12 binding and bind CXCR4wild type and CXCR4-WHIM (R334X/S338X) mutants and with (sub-) nanomolar affinities. The nanobodies' epitope was mapped to extracellular loop 2 of CXCR4, overlapping with the binding site of CXCL12. Monovalent, and in particular bivalent, nanobodies were more potent than AMD3100 in reducing CXCL12-mediated G protein activation. In addition, CXCR4-WHIM-dependent calcium flux and wound healing of human papillomavirus-immortalized cell lines in response to CXCL12 was effectively inhibited by the nanobodies. Based on these in vitro results, we conclude that CXCR4 nanobodies hold significant potential as alternative therapeutics for CXCR4-associated diseases such as WHIM syndrome.

\section{Introduction}

WHIM syndrome is a rare congenital immunodeficiency disease caused by aberrant activity of the chemokine CXCL12/ CXCR4 axis (Hernandez et al., 2003; Bachelerie, 2010). The disease is named after its main four clinical manifestations: human papillomavirus (HPV)-induced warts, hypogammaglobulinemia, recurrent bacterial infections, and myelokathexis (Gorlin et al., 2000; Hernandez et al., 2003). WHIM syndrome patients are generally panleukopenic and display a combination of WHIM syndrome-induced immunodeficiencies

This work was supported by the Netherlands Organization for Scientific Research [Vici Grant] and the Dutch Technology Foundation.

${ }^{1}$ Current affiliation: Department of Drug Design and Pharmacology, Faculty of Health and Medical Sciences, University of Copenhagen, Copenhagen, Denmark.

${ }^{2}$ Current affiliation: Merus N.V., Utrecht, The Netherlands.

https://doi.org/10.1124/jpet.117.242735.

S This article has supplemental material available at jpet.aspetjournals.org.
(Kawai and Malech, 2009; McDermott et al., 2011a). In addition to a selective susceptibility to HPV-mediated pathogenesis (cutaneous and genital warts that cannot be controlled and might progress to cancer), patients are prone to recurrent bacterial infections and can develop various malignancies, including Epstein-Barr virus-associated lymphoproliferative diseases or primary cutaneous follicle center lymphoma (Imashuku et al., 2002; Chow et al., 2010; Beaussant Cohen et al., 2012; Yoshii et al., 2015; Meuris et al., 2016). WHIM syndrome is primarily caused by heterozygous autosomal dominant CXCR4 mutations within the $\mathrm{C}$ terminus of the receptor. Although the mutations are heterogeneous, they are all located in the region encoding for the carboxyl terminus of the receptor, resulting in four nonsense and four frameshift truncation mutations (Beaussant Cohen et al., 2012; Al Ustwani et al., 2014; Liu et al., 2016) and one single point substitution (E343K) mutation (Liu et al., 2012). The most common WHIM variants are the R334X and S338X truncation mutants, which lack either 19 or 15 residues from the

ABBREVIATIONS: BSA, bovine serum albumin; CRE, cAMP response element; DMEM, Dulbecco's modified Eagle's medium; ECL2, extracellular loop 2; FBS, fetal bovine serum; HPV, human papillomavirus; IP, inositol phosphate; PBS, phosphate-buffered saline; WHIM, warts, hypogammaglobulinemia, infections, and myelokathexis; WT, wild type. 
C terminus (Table 1) (McDermott et al., 2011b; Ballester et al., 2016). These WHIM mutations render CXCR4 hyperresponsive to its ligand CXCL12 together with impaired desensitization and internalization of the mutant receptor (Balabanian et al., 2005). Interestingly, besides the germline CXCR4 mutations in WHIM syndrome, somatic WHIMlike mutations are found in $30 \%$ of the patients with Waldenström's macroglobulinemia, which have been correlated to tumor progression and drug resistance (Hunter et al., 2014; Roccaro et al., 2014; Kapoor et al., 2015). Interestingly, distinct genetic mechanisms (e.g., germline versus somatic) are associated with identical or highly similar mutations in the CXCR4 C-terminal region (Liu et al., 2016). CXCR4 is widely expressed on leukocytes (Förster et al., 1998; Lee et al., 1999) and plays a role in retention and homing of cells to the bone marrow (Ma et al., 1999), CXCR4 mutations also affect immunologic processes and result in decreased levels of circulating leukocytes and immunoglobulins (Bock et al., 2014; Brault et al., 2014). Considering the broad functions of CXCR4 in maintaining leukocyte homeostasis, patients suffering from WHIM syndrome display altered immune responses, likely as a consequence of impairment in the differentiation and trafficking of leukocytes (McDermott et al., 2015; Biajoux et al., 2016; Freitas et al., 2017).

Currently, WHIM syndrome treatments consist of symptom relief, which do not target the aberrant CXCR4 signaling and are moderately effective. Treatments range from granulocyte colony-stimulating factor to induce the release of immune cells from bone marrow to prophylactic antibiotics against respiratory bacterial infections and intravenously administered immunoglobulins to compensate the hypogammaglobulinemia (Kawai and Malech, 2009). However, phase 1 clinical studies of the low molecular weight CXCR4 antagonist AMD3100 (plerixafor, Mobozil) have demonstrated the potential of targeting CXCR4 in WHIM syndrome therapy (Dale et al., 2011; McDermott et al., 2011a, 2014). AMD3100 is a Food and Drug Administration (FDA) approved drug for stem-cell mobilization in non-Hodgkin's lymphoma and multiple myeloma. In addition, AMD3100 treatment effectively corrected panleukopenia (McDermott et al., 2011a), decreased the disease burden, and was relatively safe for both long-term (6 months) and low-dose use in WHIM patients (McDermott et al., 2014). However, in a different setting, single-dose or short-term AMD3100 treatment was also associated with side effects such as abdominal bloating, diarrhea, headache, nausea, lightheadedness, facial paresthesias, and injection-site erythema (Liles et al., 2003; Devine et al., 2004). Long-term AMD3100 treatment of human immunodeficiency virus (HIV) infections was discontinued due to potential cardiac toxicity (Scozzafava et al., 2002; De Clercq, 2003). AMD3100 is also associated with suboptimal pharmacokinetic characteristics, such as a

TABLE 1

Alignment of CXCR4-WT and WHIM C-terminal amino acid sequences

\begin{tabular}{lcccc}
\hline \multirow{2}{*}{ CXCR4 } & \multicolumn{4}{c}{ C-Terminal Sequence } \\
\cline { 2 - 5 } & aa 321-330 & \multicolumn{1}{c}{ aa 331-340 } & aa 341-350 & aa 351-352 \\
\hline WT & SV SRGSSLKILS & KGKRGGHSSV & STESESSSFH & SS \\
R334X & SV SRGSSLKILS & KGK & & \\
S338X & SV SRGSSLKILS & KGKRGGH & & \\
\hline
\end{tabular}

aa, amino acid. short in vivo half-life (3.5 hours) and limited oral bioavailability (Hendrix et al., 2000). Altogether, this illustrates that treating WHIM syndrome by targeting CXCR4 might be effective but it needs to be targeted more safely.

The nanobody platform provides an alternative strategy to target CXCR4-WHIM signaling. Nanobodies are $12-15 \mathrm{kDa}$ recombinant single-domain antibody fragments and have advantages over small-molecule drugs in terms of target affinity and specificity. Another benefit of nanobodies is their modular structure, which conveniently allows the generation of multivalent nanobody formats to improve functional affinity, increase in vivo half-life bispecific targeting, and/or allow tissue-specific targeting (Els Conrath et al., 2001; Mujić-Delić et al., 2014). Because of their size and molecular structure, nanobodies more readily recognize buried epitopes (e.g., G protein-coupled receptor ligand-binding pockets) compared with conventional antibodies and have high protein stability and low immunogenicity (Steyaert and Kobilka, 2011; Mujić-Delić et al., 2014; Peyvandi et al., 2016). Previously, we described CXCR4-specific nanobodies that antagonized CXCL12-dependent binding/signaling and inhibited HIV infection (Jähnichen et al., 2010). In this study, we evaluated the potential of CXCR4-targeting nanobodies as WHIM syndrome therapeutics and compared their potencies in their ability to displace CXCL12 binding and inhibit CXCL12-induced signaling of both CXCR4-wild type (WT) and CXCR4-WHIM mutants.

\section{Materials and Methods}

\section{Materials}

The CXCR4 ligands and recombinant human CXCL12 were obtained from Peprotech (Rocky Hill, NJ) and AMD3100 (1,1' -[1,4phenylenebis-(methylene)]-bis-1,4,8,11-tetraazacyclotetra-decane) was obtained from Sigma-Aldrich (St. Louis, MO). The 12G5 monoclonal CXCR4 antibody was purchased from R\&D systems (Minneapolis, MN). Linear $25 \mathrm{kDa}$ polyethylenimine for transient transfections was obtained from Polysciences (Eppelheim, Germany). Dulbecco's modified Eagle's medium (DMEM) and Trypsin-EDTA were purchased from Sigma-Aldrich. Fetal bovine serum (FBS) and penicillin/streptomycin were obtained from PAA Laboratories GmbH (Paschen, Austria). For coating of cell culture plates, poly-L-lysine solution was obtained from Sigma-Aldrich, and ${ }^{125} \mathrm{I}-\mathrm{CXCL} 12(2200 \mathrm{Ci} / \mathrm{mmol})$ and myo- $\left[2-{ }^{3} \mathrm{H}\right]$ inositol $(1 \mathrm{mCi} / \mathrm{ml})$ were obtained from Perkin Elmer Life Sciences (Boston, MA). Phospho-ERK1/2 (Thr202/Tyr204), total ERK1/2, and anti-Myc tag (9B11) antibodies were obtained from Cell Signaling Technology (Danvers, MA). Anti-rabbit and anti-mouse horseradish peroxidase-conjugated antibodies were obtained from Bio-Rad Laboratories (Hercules, CA). Anti-mouse Alexa Fluor 488-conjugated antibody (A11001) was obtained from Thermo Fisher Scientific (Waltham, MA).

\section{Phage-Display Selection}

Immunization, construction of the nanobody phage libraries, and phage-display selections were performed as described previously (Jähnichen et al., 2010).

\section{Molecular Biology and Nanobody Production}

pcDNA3.1-CXCR4-WT (GenBank: AF025375.1), a gift from Dr. C.P. Tensen (Leiden University Medical Center, Leiden, The Netherlands), was used as template DNA to generate CXCR4-WT, CXCR4-R334X, 
and CXCR4-S338X by polymerase chain reaction (PCR) using specific primers. The primer sequences were the following:

\section{WT-FW: 5'-CAG GTACCGCCACCATGGAGGGGATCAGTATA- TACACT-3'; \\ WT-REV: 5'-ATTTCTAATTAGCTGGAGTGAAAACTTGAAGA-3'; R334X-REV: 5' - CCCCTCTAGATCACTTTCCTTTGGAGAG- GATCTTGAGG-3'; and \\ S338X-REV: 5'-TTTTCTAGATTAATGTCCACCTCGCTTTCCTT- TG-3'.}

The forward primer encodes a $5^{\prime} \mathrm{KpnI}$ restriction site, whereas the reverse primers encode a $3^{\prime} \mathrm{XbaI}$ restriction site. The amplified PCR fragments and the mammalian expression vector $\mathrm{pcDEF}_{3}$ (gift from J.A. Langer from Robert Wood Johnson Medical School, Piscataway, $\mathrm{NJ}$ ) were digested with $\mathrm{KpnI}$ and $\mathrm{XbaI}$ enzymes and the fragments were ligated into $\mathrm{pcDEF}_{3}$ using $\mathrm{T} 4 \mathrm{DNA}$ ligase. The point-mutated CXCR4 constructs D187V, F189V, and V196E in pcDNA3 were kindly provided by Ablynx N.V. The mutants were subcloned to the $\mathrm{pcDEF}_{3}$ vector by PCR, the template DNA was amplified, and restriction sites were added by using the WT forward and reverse primers. All generated DNA constructs were verified by sequencing. All enzymes and buffers used for cloning were obtained from Thermo Fisher Scientific. For nanobody production, BL21 Escherichia coli cells were transformed with 10A10-PAX100 and 10A10-35GS-10A10-PAX100 DNA. Periplasmic nanobody expression was induced by addition of $1 \mathrm{mM}$ isopropyl- $\beta$-D-thiogalactopyranoside (Sigma-Aldrich) to the culture medium. Periplasmic extracts were obtained by a freezethaw cycle of the cell pellet and resuspension in phosphate-buffered saline (PBS). The $\mathrm{His}_{6}$-tagged nanobodies were purified from the periplasmic extract by ion-metal affinity chromatography using Ni-NTA agarose resin (Thermo Fisher Scientific) according to the manufacturer's instructions. Finally, a buffer exchange to PBS was performed by SnakeSkin (Thermo Fisher Scientific) dialysis or PD-10 desalting columns (GE healthcare, Little Chalfront, United Kingdom).

\section{Cell Culture}

The human embryonic kidney cell line HEK293T was cultured in DMEM (Sigma-Aldrich). The human leukemic K562 cell lines (parental, pcDNA3.1-CXCR4-WT and pcDNA3.1-CXCR4-R334X) have been previously described (McDermott et al., 2011b) and were a kind gift from David McDermott and Philip Murphy (National Institutes of Health (NIH), Bethesda, MD). The cells were cultured in RPMI-1640 (Sigma-Aldrich). The stably transfected K562 cells were cultured with $0.4 \mathrm{mg} / \mathrm{ml} \mathrm{G} 418$ (Duchefa, Haarlem, The Netherlands) for selection. All growth media were supplemented with $10 \%$ (v/v) FBS, $50 \mathrm{IU} / \mathrm{ml}$ penicillin, and $50 \mu \mathrm{g} / \mathrm{ml}$ streptomycin (PAA Laboratories GmbH, Cölbe, Germany). Cells were grown at $37^{\circ} \mathrm{C}$ in a humidified atmosphere with $5 \% \mathrm{CO}_{2}$ and passaged two times per week. Transient transfections were performed using the polyethylenimine method (Schlaeger and Christensen, 1999).

\section{${ }^{125} \mathrm{I}-\mathrm{CXCL12}$ Displacement}

Two million HEK293T cells were seeded in $10 \mathrm{~cm}$ cell culture dishes. After overnight cell growth the cells were transiently transfected with $250 \mathrm{ng}$ hCXCR4-WT, hCXCR4-R334X, or hCXCR4-S338X pcDEF3 supplemented to $5 \mu \mathrm{g}$ using empty pcDEF3 vector. Fortyeight hours post-transfection the CXCR4-expressing cell membranes were isolated as previously described (de Wit et al., 2016). Radioligand displacement assays were performed as previously described (de Wit et al., 2016). Briefly, in 96 -well plates, approximately $75 \mathrm{pM}$ ${ }^{125} \mathrm{I}$-CXCL12 in HEPES binding buffer (HBB, 50 mM HEPES-HCl, $\mathrm{pH}$ $7.4,1 \mathrm{mM} \mathrm{CaCl}_{2}, 5 \mathrm{mM} \mathrm{MgCl}_{2}, 0.1 \mathrm{M} \mathrm{NaCl}, 0.5 \%$ (w/v) bovine serum albumin (BSA)) was added to increasing concentrations of unlabeled CXCL12, AMD3100, 10A10, or 10A10-10A10 nanobodies. Radioligand only and radioligand $+100 \mathrm{nM}$ CXCL12 were used as total binding and nonspecific binding controls in each assay plate. The ligands were incubated with $5 \mu \mathrm{g} /$ well CXCR4 (WT, R334X, and S338X) or mock HEK293T membranes for 2 hours at $20^{\circ} \mathrm{C}$ to reach binding equilibrium. The radioligand-bound membranes were harvested on $0.5 \%$ (w/v) polyethylenimine-soaked GF/C filter plates (Perkin-Elmer Life Sciences) and dried for 30 minutes at $60^{\circ} \mathrm{C}$. Scintillation fluid (MicroScint-O, Perkin-Elmer) was added and radioactivity was measured using a MicroBeta liquid scintillation counter (Perkin-Elmer Life Sciences). In addition to the radioligand competition plates, the fixed amount of radioligand was also directly added to a GF/C filter plate during each experiment to determine the radioligand concentration in the displacement assay. The data were plotted and analyzed using a competitive one-site homologous binding fit for homologous displacement and a competitive one-site $\log \mathrm{IC}_{50}$ binding fit for heterologous displacement with GraphPad Prism 6 (GraphPad Software Inc., San Diego, CA).

\section{Cell Surface Expression Enzyme-Linked Immunosorbent Assay (ELISA)}

Transiently transfected HEK293T cells $\left(6 \times 10^{4}\right.$ were seeded in poly-L-lysine-coated 96 -well cell culture plates and grown at $37^{\circ} \mathrm{C}$. Forty-eight hours post-transfection cells were fixed for 5 minutes with $4 \%$ formaldehyde (Sigma-Aldrich) in PBS. The cells were washed with PBS and incubated with blocking buffer [5\% fat-free milk powder (Sigma-Aldrich) diluted in PBS] for 1 hour. This was followed by incubation with mouse-anti-CXCR4 (clone 12G5), diluted 1:200 in blocking buffer for 1 hour. After each antibody incubation the cells were washed three times with PBS, and then the cells were incubated for 1 hour with the goat anti-mouse $\operatorname{IgG}(\mathrm{H}+\mathrm{L})$-horseradish peroxidase-conjugated antibody (Bio-Rad, 1:2500). For colorimetric detection, $2 \mathrm{mM}$ o-phenylenediamine substrate solution (SigmaAldrich) in $35 \mathrm{mM}$ citric acid, $66 \mathrm{mM} \mathrm{Na}_{2} \mathrm{HPO}_{4}, 0.015 \% \mathrm{H}_{2} \mathrm{O}_{2}, \mathrm{pH}$ 5.6 was added to the cells. The reaction was terminated after 5 minutes by adding $\mathrm{H}_{2} \mathrm{SO}_{4}(1 \mathrm{M})$, and absorbance $(490 \mathrm{~nm})$ was measured in a PowerWave plate reader (BioTek, Winooski, VT).

\section{Immunofluorescence Microscopy Imaging}

Transiently transfected (mock or CXCR4) HEK293T cells $\left(6 \times 10^{4}\right.$ were seeded in poly-L-lysine-coated 96 -well cell culture plates and grown at $37^{\circ} \mathrm{C}$. Forty-eight hours post-transfection the cells were fixed for 5 minutes with $4 \%$ formaldehyde (Sigma-Aldrich) in PBS. The cells were washed with PBS, and if necessary permeabilized with $0.5 \%(\mathrm{v} / \mathrm{v}) \mathrm{NP}-40$ substituted in PBS for 30 minutes at $20^{\circ} \mathrm{C}$. Cells were incubated with blocking buffer [5\% (w/v) BSA in PBS] for 1 hour. This was followed by 10A10-10A10 (100 nM in blocking buffer) incubation for 1 hour at $20^{\circ} \mathrm{C}$. After each nanobody/antibody incubation the cells were washed three times with PBS. Subsequently, Myc-tag antibody (1:1000 in blocking buffer) and the secondary anti-mouse Alexa Fluor 488-conjugated antibody (1:500 in blocking buffer) was applied for 1 hour at $20^{\circ} \mathrm{C}$. Cell nuclei were stained using $4^{\prime}, 6$-diamidino-2phenylindole $(1 \mu \mathrm{g} / \mathrm{ml})$ in PBS for 5 minutes at $20^{\circ} \mathrm{C}$. Immunofluorescence imaging was carried out using an FSX-100 microscope (Olympus, Tokyo, Japan).

\section{Cell Surface Radioligand Binding}

Transiently transfected (mock, hCXCR4-WT, mCXCR4-WT, or hCXCR7) HEK293T cells were seeded in poly-L-lysine-coated 96-well cell culture plates. Forty-eight hours after transfection the culture medium was removed and the cells were incubated with $75 \mathrm{pM}^{125} \mathrm{I}-\mathrm{CXCL} 12 \mathrm{with} /$ without cold ligands (CXCL12, AMD3100, and 10A10) in HEPES binding buffer with $0.5 \%$ (w/v) BSA and incubated at $4^{\circ} \mathrm{C}$ for 3 hours until binding equilibrium was reached. The cells were washed three times with ice-cold HEPES wash buffer (HEPES binding buffer $+0.5 \mathrm{M} \mathrm{NaCl}$ ). Cells were lysed with radioimmunoprecipitation assay buffer (RIPA), and the cell lysate was transferred to radioactivity counting vials and measured with a Wallac Compugamma counter (Perkin Elmer Life Sciences). 


\section{SDS-PAGE and Western Blotting}

Transiently transfected (mock, CXCR4-WT, CXCR4-R334X, or CXCR4-S338X) HEK293T cells $\left(3 \times 10^{5}\right)$ cells were grown on a 12 -well plate on full medium. Cells were synchronized by serum starvation with 0\% FBS DMEM and grown overnight. Synchronized cells were treated with CXCL12 $(1 \mathrm{nM})$, AMD3100 $(10 \mu \mathrm{M}), 10 \mathrm{~A} 10$ $(1 \mu \mathrm{M})$, and/or 10A10-10A10 (100 nM). For the CXCL12 inhibition experiments, cells were preincubated for 1 hour at $37^{\circ} \mathrm{C}$ with the CXCR4 inhibitors prior to CXCL12 stimulation ( $1 \mathrm{nM})$. After 5 or 15 minutes of CXCL12 stimulation the cells were lysed on ice with RIPA buffer supplemented with $1 \mathrm{mM} \mathrm{NaF}, 1 \mathrm{mM} \mathrm{NaVO}$, and protease inhibitor cocktail (cOmplete, Roche, Basel, Switzerland), sonicated, and centrifuged to remove insoluble cell debris. Protein content of the lysates was determined using bicinchoninic acid assay (BCA) protein estimation according to the manufacturer's instructions (Thermo Fisher Scientific). Equal amounts of protein were resolved by SDS-PAGE analysis using $10 \%$ acrylamide gels. After electrophoresis, protein was blotted to Polyvinylidene difluoride (PVDF) membranes (Bio-Rad), which was subsequently blocked for 1 hour at $22^{\circ} \mathrm{C}$ in $5 \%$ nonfat milk in $0.1 \%$ Tween-20/Tris-buffered saline (TBS) solution. Western blot was performed according to standard procedure and blotted against Phospho-ERK1/2 (Thr202/Tyr204, 1:1000), total ERK1/2 (1:1000) (Cell Signaling Technology), or $\beta$-actin (SigmaAldrich, 1:2500). Next, the membranes were incubated with secondary anti-mouse or anti-rabbit horseradish peroxidase-conjugated antibodies (Bio-Rad Laboratories, 1:5000). The Western blot images were acquired by enhanced chemiluminescence solution (ECL) (Perkin Elmer Life Sciences) and a Chemi Doc imager (Bio-Rad Laboratories), and the signal was quantified by densitometry using the Image Lab software (Bio-Rad Laboratories).

\section{Flow Cytometry}

HEK293T cells were transiently transfected with $100 \mathrm{ng}$ hCXCR4WT, D187V, F189V, or V196E receptor DNA, supplemented to $5 \mu \mathrm{g}$

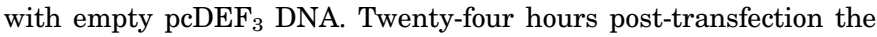
cells were dissociated with nonenzymatic cell dissociation buffer (Sigma-Aldrich), and $1 \times 10^{5}$ cells/well were seeded in clear 96 -well U-bottom plates in assay buffer (ice-cold PBS supplemented with 5\% FBS), after which cells were incubated with increasing concentrations of 10A10-10A10 nanobodies in assay buffer at $4^{\circ} \mathrm{C}$. Cells were washed three times with ice-cold assay buffer. Subsequently, cells were incubated with the primary Myc-tag antibody (Cell Signaling Technology, 9B11, 1:1000) in assay buffer for 1 hour at $4^{\circ} \mathrm{C}$. Cells were washed three times with ice-cold assay buffer. Finally, cells were incubated with the secondary fluorescent anti-mouse IgG $(\mathrm{H}+\mathrm{L})$ polyclonal antibody Alexa 488 (Thermo Fisher Scientific, A11001) for 1 hour at $4^{\circ} \mathrm{C}$. Afterward, cells were washed three times with ice-cold assay buffer. Fluorescence-assisted flow cytometry was performed on a Guava Easycyte (Guava Technologies, MERCK Millipore, Billerica, MA). Data were analyzed using GraphPad Prism version 6.0 (GraphPad Software, Inc., La Jolla, CA). Specific binding was plotted as mean fluorescent counts of ungated samples. Background subtraction of unspecific binding was performed using the values obtained from the mock-transfected samples. Curves were fitted using the one-site specific-binding algorithm $\left[Y=B_{\max } \times\right.$ $\left.X /\left(K_{\mathrm{d}}+X\right)\right]$ in GraphPad Prism 6.0.

\section{Phospholipase C Activation}

HEK293T cells $\left(4 \times 10^{6}\right)$ were transiently transfected with $100 \mathrm{ng}$ hCXCR4-WT, R334X, or S338X receptor DNA, $2.5 \mu \mathrm{g} \mathrm{G} \alpha_{\text {qi5 }}$ DNA, and $2.4 \mu \mathrm{g} \mathrm{pcDEF}{ }_{3}$ DNA. Twenty-four hours post-transfection cells $(1.2 \times$ $10 \%$ well) were seeded in poly-L-lysine-coated flat-bottom 48 -well plates and labeled overnight with myo-[2-3H]-inositol $(1 \mu \mathrm{Ci} / \mathrm{ml})$ in Earle's inositol-free minimal essential medium supplemented with $10 \%$ FBS and $1 \%$ penicillin/streptomycin $(\mathrm{P} / \mathrm{S})$. The next day, the labeling medium was aspirated and the cells were stimulated with
CXCL12 (agonist mode) in assay buffer (20 mM HEPES, $140 \mathrm{mM}$ $\mathrm{NaCl}, 5 \mathrm{mM} \mathrm{KCl}, 1 \mathrm{mM} \mathrm{MgSO}_{4}, 1 \mathrm{mM} \mathrm{CaCl}_{2}, 10 \mathrm{mM}$ glucose) supplemented with $0.05 \% \mathrm{BSA}$ and $10 \mathrm{mM} \mathrm{LiCl}$. In the antagonistmode experiments, the cells were preincubated with antagonist solutions in assay buffer supplemented with $0.05 \%$ BSA for 5 minutes at $20^{\circ} \mathrm{C}$, prior to addition of $5 \mathrm{nM}\left(\mathrm{EC}_{80}\right)$ CXCL12 solutions in assay buffer supplemented with $0.05 \%$ BSA and $10 \mathrm{mM} \mathrm{LiCl}$. After 1.5-hour incubation at $37^{\circ} \mathrm{C}$, inositol phosphate (IP) accumulation was terminated by placing the cells on ice and aspirating the stimulation buffer prior to the addition of ice-cold $10 \mathrm{mM}$ formic acid to permeabilize the cells. After 1-hour incubation on ice, the $\left[{ }^{3} \mathrm{H}\right]$-inositol phosphates were isolated by anion-exchange chromatography (Dowex AG1-X8 columns; Bio-Rad) in counting vials. Scintillation fluid (Perkin Elmer Life Sciences) was added and the samples were counted by a Packard TriCarb Liquid Scintillation Analyzer (Perkin Elmer Life Sciences) (2 minutes/vial). Data were analyzed using GraphPad Prism version 6.0 (GraphPad Software, Inc.). Agonist mode curves were fitted using the dose-response $\log$ (agonist) versus response equation $\left[Y=\right.$ Bottom $+($ Top - Bottom $\left.) /\left(1+10^{\operatorname{logEC} 5_{50-X}}\right)\right]$ in GraphPad Prism version 6.0 (GraphPad Software, Inc.). The CXCL12 $\mathrm{EC}_{80}$ values were determined from the obtained $\mathrm{EC}_{50}$ values by using the following equation: $\mathrm{EC}_{\mathrm{f}}=(\mathrm{f} / 100-\mathrm{f})^{1 / \mathrm{H}} \times \mathrm{EC}_{50}$, where $\mathrm{f}$ stands for 80 and $\mathrm{H}$ is the Hill slope. The antagonist-mode dose-response curves of 10A10 nanobodies and AMD3100 in competition with a fixed $5 \mathrm{nM}$ CXCL12 were fitted with the $\log$ (inhibitor) versus response algorithm $Y=$ Bottom $+($ Top - Bottom $) /\left(1+10^{X-\log _{50}}\right)$ in GraphPad Prism version 6.0 (GraphPad Software, Inc.).

\section{Reporter Gene}

HEK293T cells were transiently transfected with the cAMP response element (CRE) luciferase reporter gene and CXCR4-WT, CXCR4-R334X, or CXCR4-S338X. Briefly, $1 \times 10^{6}$ cells were transfected with CXCR4-pcDEF 3 (250 ng) and $1 \mu \mathrm{g}$ CRE-luc vector supplemented with empty $\mathrm{pcDEF}_{3}$ vector to a total of $2 \mu \mathrm{g}$. Transfected cells were seeded in white-bottom 96-well assay plates and grown overnight at $37^{\circ} \mathrm{C}$. For the agonist mode, cells are incubated with increasing concentrations $\left(10^{-13}\right.$ to $\left.10^{-7} \mathrm{M}\right)$ of CXCL12 and $1 \mu \mathrm{M}$ forskolin in DMEM. For CXCL12 inhibition (antagonist mode), the cells were incubated with $1 \mathrm{nM}\left(\mathrm{EC}_{80}\right), 1 \mu \mathrm{M}$ forskolin, and increasing concentrations of antagonist (AMD3100, 10A10, or 10A10-10A10). After 6 hours of stimulation at $37^{\circ} \mathrm{C}$, the medium was aspirated and the cells were lysed by addition of $25 \mu$ l LAR reagent $[0.83 \mathrm{mM}$ ATP, $0.83 \mathrm{mM}$ D-luciferine, $18.7 \mathrm{mM} \mathrm{MgCl}{ }_{2}, 0.78 \mu \mathrm{M} \mathrm{Na}_{2} \mathrm{HPO}_{4}, 38.9 \mathrm{mM}$ Tris-HCl (pH 7.8), 0.39\% glycerol, $0.03 \%$ Triton X-100, and $2.6 \mu \mathrm{M}$ DTT]. Luminescence (1 second per well) was measured in a Mithras LB 940 Multimode Plate Reader (Berthold Technologies) after 30 minutes of incubation at $37^{\circ} \mathrm{C}$. The data were plotted and fitted [dose-response stimulation (agonist mode) or dose-response inhibition (antagonist mode), three parameters] using Graphpad Prism version 6.0 (GraphPad Software, Inc.).

\section{Intracellular Calcium Flux}

K562 cells were seeded $\left(1 \times 10^{5}\right.$ cells/well, $\left.50 \mu \mathrm{l}\right)$ in assay buffer [Hanks' balanced saline solution (Sigma-Aldrich) supplemented with $0.05 \% \mathrm{BSA}$ and $20 \mathrm{mM}$ of HEPES at pH 7.4] in black, clear-bottom 96-well plates and allowed to settle for 1 hour in a humidified growth chamber at $37^{\circ} \mathrm{C}$ with $5 \% \mathrm{CO}_{2}$. Afterward, $20 \mu \mathrm{l}$ of $7 \times$ concentrated antagonist dilution made in assay buffer was added to the required wells. In the agonist-mode case, $20 \mu \mathrm{l}$ of assay buffer was added to the wells. According to manufacturer's instructions (Fluo-4 NW Calcium Assay Kit, Molecular Probes, Thermo Fisher Scientific), intracellular calcium was labeled by the addition of $50 \mu \mathrm{l}$ of a Fluor-4 NW dye solution prepared in assay buffer and supplemented with $5 \mathrm{mM}$ probenecid acid to each well followed by 30 -minute incubation in the dark at $37^{\circ} \mathrm{C}$. Intracellular calcium fluxes were measured on the NOVOstar Microplate Reader (BMG Labtech, Ortenberg, Germany) during a total measurement time span of 110 seconds per well at a 
temperature of $37^{\circ} \mathrm{C}$. Initially, baseline fluorescence was measured for 9 seconds, after which cells were stimulated with $20 \mu \mathrm{l}$ of $7 \times$ final concentration CXCL12 solution. The agonist injection time span was 7 seconds and fluorescence measurements thus continued from $t=$ 16 seconds. The calcium trace was recorded for 74 seconds $(t=$ 90 seconds) after agonist stimulation, after which $50 \mu \mathrm{l}$ of a $5 \%(\mathrm{v} / \mathrm{v})$ Triton-X100 (Sigma-Aldrich)/assay buffer was added to lyse cells. The total calcium fluorescence was measured for a duration of 20 seconds until $t=110$ seconds. Data were subsequently analyzed using GraphPad Prism version 6.0 (GraphPad Software, Inc.).

\section{Wound-Healing Assay}

Wound-healing assays were performed as described previously (Chow et al., 2010). In short, $1 \times 10^{5}$ HPV18 immortalized human keratinocytes were seeded on gelatin-fibronectin-coated coverslips and grown to confluence in complete Keratinocyte Serum-Free Growth Medium (KSFM) medium. Cells were scratched and incubated with or without nanobodies or AMD3100 for 16 hours. Cells were fixed and subsequently stained for polymeric $\mathrm{F}$ actin and nuclei using Tetramethylrhodamine (TRITC)-tagged phalloidin and Hoechst 33342 , respectively. Scratch closure was then visualized by immunofluorescence microscopy. The size of the wound was automatically calculated using the Axiovision 4.6 software (Zeiss, Oberkochen, Germany).

Data Analyses. All data were obtained from at least three independent experiments in triplicates. All bar graphs and statistical analyses were obtained with the GraphPad Prism 6 software (GraphPad software Inc.). Bars and errors represent the mean \pm S.E.M; ${ }^{*} P<0.05$ values as determined by unpaired $t$ test.

\section{Results}

WHIM syndrome-associated CXCR4 mutations, such as CXCR4-R334X and CXCR4-S338X, possess a truncated C-terminal tail (Table 1). Homologous CXCL12 radioligand displacement studies on HEK293T membranes showed similar CXCL12 binding affinities for CXCR4-WT, -R334X, and $-\mathrm{S} 338 \mathrm{X}\left(\mathrm{p} K_{\mathrm{i}}\right.$ values of $10.4 \pm 0.4,10.4 \pm 0.8$, and $10.0 \pm 0.4$, respectively, Fig. 1A). Next, the effect of WHIM mutations on ligand-induced $\mathrm{G}$ protein signaling was assessed. Coexpression of the chimeric G-protein $\mathrm{G} \alpha_{\mathrm{qi} i 5}$ redirects CXCR4 signaling from the $\mathrm{G} \alpha_{\mathrm{i}}$ pathway to $\mathrm{G} \alpha_{\mathrm{q}}$-mediated phospholipase $\mathrm{C}$ activation, which can be readily quantified via IP accumulation (Conklin et al., 1993). CXCL12 induced equipotent increases of CXCR4WT-, -R334X-, or -S338X-mediated IP accumulation $\left(\mathrm{pEC}_{50}\right.$ values of $8.8 \pm 0.1,8.90 \pm 0.07$, and $8.90 \pm 0.08$, respectively, Fig. 1B), while no effect was observed in mock-transfected cells (Supplemental Fig. 1A). Moreover, at a similar expression level (Fig. 1C) a 2-fold increase in maximum response of CXCL12induced IP accumulation was observed for the two CXCR4WHIM receptors compared with CXCR4-WT. CXCL12 also results in CXCR4-mediated activation of the mitogen-activated protein kinase (MAPK) pathway. Therefore, we compared the CXCL12-induced ERK1/2 activation (phosphorylated at Thr202/Tyr204) by CXCR4-WT and WHIM mutant S338X (Fig. 1D). Compared with the WT, CXCR4-S338X displayed a sustained increase in phosphorylation of Thr202/Tyr204 ERK1/2 levels upon CXL12 exposure. Taken together, although CXCL12 binding affinities and potencies are identical between WT and WHIM receptors, the degree of signaling of WHIM receptors is increased and prolonged.

As a novel approach to inhibit the hyperactivation of CXCR4-WHIM mutants, new CXCR4-targeting nanobodies were selected, of which nanobody 10A10 was selected as the

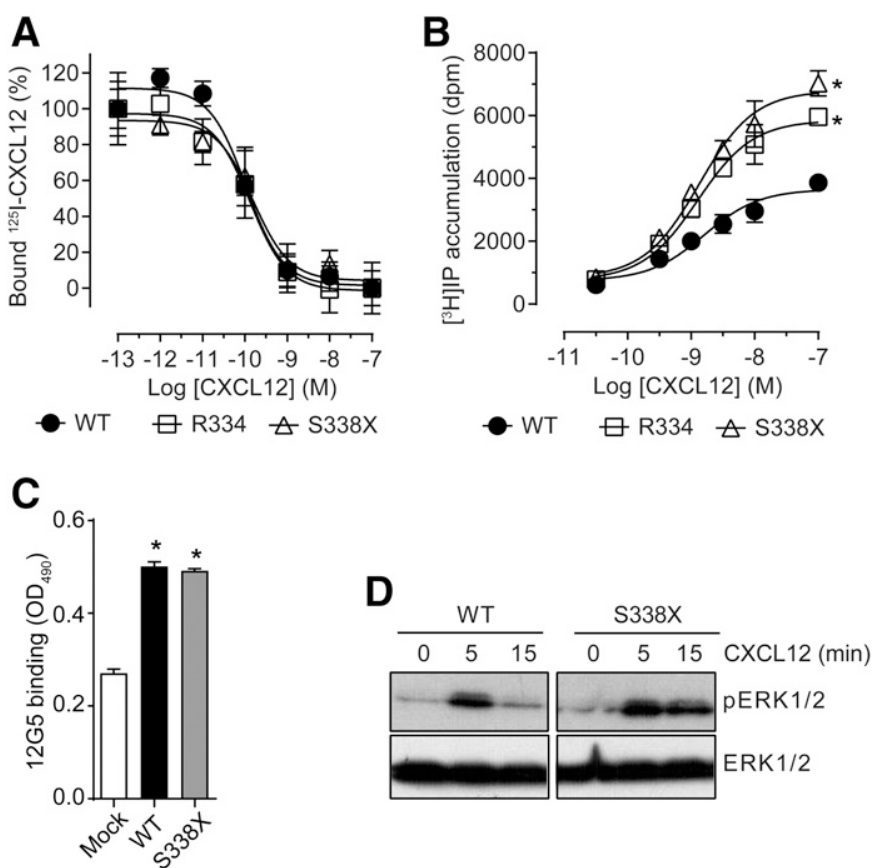

Fig. 1. WHIM mutation in CXCR4 sustains CXCL12-induced signaling. (A) Binding of ${ }^{125}$ I-labeled CXCL12 to HEK293T membranes containing either WT CXCR4 (solid circles) or two WHIM mutants R334X (open squares) and S338X (open triangles). (B) CXCL12-induced accumulation of $\left[{ }^{3} \mathrm{H}\right]$-inositol phosphates in HEK293T cells expressing either CXCR4-WT or WHIM mutants R334X or S338X. CXCR4-mediated phospholipase C activation was obtained by coexpression with $\mathrm{G} \alpha_{\text {qi5 }}$. Plotted are mean and S.E.M. values. (C) Expression levels of CXCR4-WT or CXCR4S338X, as determined using 12G5 antibody in a cell surface ELISA. (D) CXCL12-induced phosphorylation of ERK1/2 at threonine 202 and tyrosine 204 , as determined by western blotting. HEK293T cells expressing either CXCR4-WT or WHIM mutant S338X were treated with CXCL12 $(100 \mathrm{nM})$ for 5 or 15 minutes. Total ERK1/2 was stained as loading control.

lead molecule. The nanobodies were produced as monovalent and bivalent nanobody constructs in which two identical 10A10 nanobodies were separated by a flexible glycine-serine $(\text { GGGGS })_{4}$ linker. These nanobodies allowed sensitive detection of cell surface and intracellularly localized CXCR4 in immunofluorescence microscopy, without any detectable background staining on mock or nontransfected cells (Fig. 2A). Both monovalent and bivalent nanobodies and the reference compound AMD3100 displaced the radioligand ( $75 \mathrm{pM}$ of ${ }^{125}$ I-CXCL12) from CXCR4 in a dose-dependent manner (Fig. 2B). The nanobodies displayed high potency in displacing CXCL12 from CXCR4-WT ( pIC $_{50}$ values of $7.7 \pm 0.2$ for monovalent and $8.8 \pm 0.1$ for bivalent) compared with AMD3100 $(6.3 \pm 0.1)$. The bivalent nanobody construct displayed a 10-fold increase in binding affinity compared with its monovalent variant, resulting in nanomolar binding affinity for CXCR4WT. On WHIM mutants, both monovalent and bivalent nanobodies could displace CXCL12 binding (partial for the monovalent nanobody and full displacement for the bivalent nanobody). The affinities of the monovalent and bivalent nanobodies for CXCR-WT and CXCR-R334X (Fig. 2A, right) or CXCR-S338X (Supplemental Fig. 1B) were comparable (Table 2).

Human CXCR4 shares high-sequence identity (90\%) with its murine ortholog and binds the same endogenous chemokine (CXCL12) as the human receptor ACKR3 (31\% sequence identity, also referred to as CXCR7) (Gravel et al., 2010). 


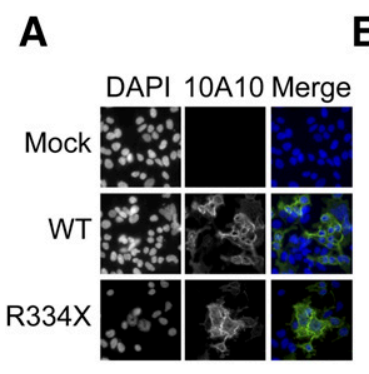

B

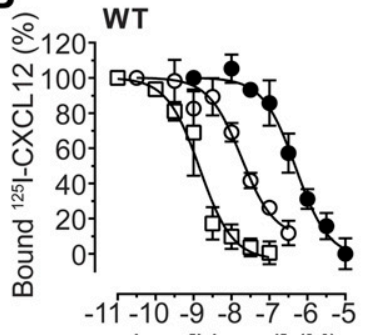

Log [Ligand] (M)

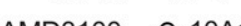

AMD3100 $\ominus 10 \mathrm{~A} 10$

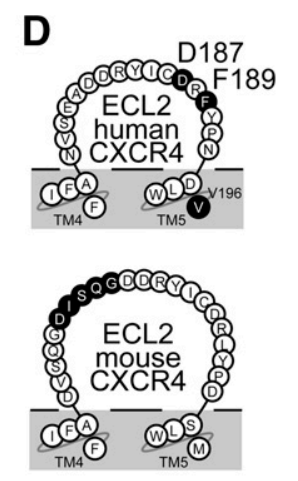

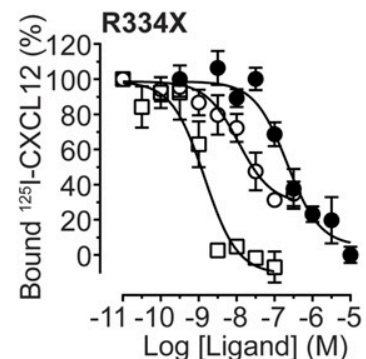

ษ 10A10-10A10

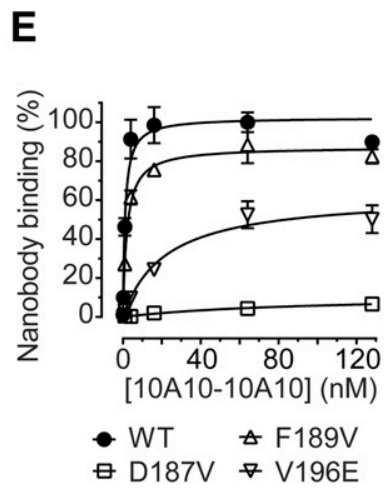

Fig. 2. Nanobodies displace CXCL12 from CXCR4-WT and WHIM mutants via binding to ECL2 of the receptor. (A) Binding of 10A10-10A10 $(100 \mathrm{nM})$ to HEK293T cells expressing CXCR4-WT or WHIM mutant R334X, as determined by immunofluorescence microscopy. (B) Binding of ${ }^{125}$ I-labeled CXCL12 (75 pM) to HEK293T membranes containing either CXCR4-WT (left) or WHIM mutant R334X (right) in the presence of a concentration range of AMD3100 (solid circles), 10A10 (open circles), or 10A10-10A10 (open squares). (C) Binding of ${ }^{125} \mathrm{I}$-CXCL12 to HEK293T membranes expressing either human- or mouse CXCR4 or human ACKR3/CXCR7 in the presence of an excess of unlabeled CXCL12 (100 nM, black) or 10A10 (1 $\mu \mathrm{M}$, gray). (D) Snake plot depicting ECL2 of human CXCR4 (top) or mouse CXCR4 (bottom). The three residues that were mutated for epitope mapping (D187, F189, and V196) are indicated in black. (E) Binding of a concentration range of 10A10-10A10 to HEK293T cells expressing either CXCR4-WT (filled circles) or the CXCR4 ECL2 mutants D187V (open squares, F189V (open triangles), or V196E (open inverted triangles), as determined by flow cytometry. Plotted are mean and S.E.M. values.
Target specificity was verified by ${ }^{125}$ I-CXCL12 displacement assays on intact HEK293T cells transiently transfected with hCXCR4, hACKR3, or mouse CXCR4 (Fig. 2C). While 10A10 fully displaced ${ }^{125} \mathrm{I}$-CXCL12 from hCXCR4, it could not displace CXCL12 from ACKR3 or mCXCR4. This indicates that the nanobody 10A10 is specific for human CXCR4. Variations between human and murine CXCR4 orthologs are predominantly found in their extracellular loop 2 (ECL2) region (Fig. 2D). For this reason, we subsequently assessed the binding of 10A10 to ECL2 point mutants of hCXCR4 (D187V, F189V, and V196E) (Fig. 2E). These point mutations were previously shown to have no effect on cell surface expression and 12G5 antibody binding (Wang et al., 1998; Jähnichen et al., 2010). While 10A10 showed high-affinity binding to both CXCR4-WT ( $K_{\mathrm{D}}$ value of $\left.8.9 \pm 0.06\right)$ and CXCR4-F189V $\left(\mathrm{p} K_{\mathrm{D}}\right.$ value of $8.7 \pm 0.03$ ), a complete lack of binding was observed for the CXCR4-D187V mutant. This indicates an essential role for the acidic residue D187 in binding of 10A10 to CXCR4.

TABLE 2

Pharmacological characteristics of CXCR4 antagonists

\begin{tabular}{|c|c|c|c|c|}
\hline Pharmacological Characteristic & CXCR4 & $10 \mathrm{~A} 10$ & 10A10-10A10 & AMD3100 \\
\hline \multicolumn{5}{|l|}{ Ligand displacement ( $\left.{ }^{125} \mathrm{I}-\mathrm{CXCL} 12\right)$} \\
\hline Binding inhibition potency $\left(\mathrm{pIC}_{50} \pm\right.$ S.E.M.) & WT & $7.58 \pm 0.08$ & $9.08 \pm 0.15$ & $6.36 \pm 0.09$ \\
\hline Binding inhibition potency $\left(\mathrm{pIC}_{50} \pm\right.$ S.E.M. $)$ & R334X & $7.83 \pm 0.07$ & $8.97 \pm 0.03$ & $6.35 \pm 0.13$ \\
\hline Binding inhibition potency $\left(\mathrm{pIC}_{50} \pm\right.$ S.E.M. $)$ & S338X & $7.68 \pm 0.11$ & $9.13 \pm 0.17$ & $6.53 \pm 0.05$ \\
\hline \multicolumn{5}{|l|}{ Binding (Flow cytometry) } \\
\hline Affinity $\left(\mathrm{pK}_{\mathrm{d}} \pm\right.$ S.E.M.) & WT & N.D. & $8.87 \pm 0.06$ & N.D. \\
\hline Affinity ( $\mathrm{pK}_{\mathrm{d}} \pm$ S.E.M.) & D187V & N.D. & N.D. & N.D. \\
\hline Affinity $\left(\mathrm{pK}_{\mathrm{d}} \pm\right.$ S.E.M. $)$ & F189V & N.D. & $8.75 \pm 0.03$ & N.D. \\
\hline Affinity $\left(\mathrm{pK}_{\mathrm{d}} \pm\right.$ S.E.M.) & V196E & N.D. & $8.00 \pm 0.03$ & N.D. \\
\hline \multicolumn{5}{|c|}{$\mathrm{G} \alpha_{\mathrm{i}}$ activation $\left(\left[{ }^{3} \mathrm{H}\right]\right.$-inositol phosphate accumulation) } \\
\hline Potency $\left(\mathrm{pIC}_{50} \pm\right.$ S.E.M.) & WT & $7.92 \pm 0.03$ & $8.28 \pm 0.04$ & $6.17 \pm 0.03$ \\
\hline Potency $\left(\mathrm{pIC}_{50} \pm\right.$ S.E.M.) & $\mathrm{R} 334 \mathrm{X}$ & $7.94 \pm 0.03$ & $8.30 \pm 0.06$ & $6.24 \pm 0.16$ \\
\hline Potency $\left(\mathrm{pIC}_{50} \pm\right.$ S.E.M.) & S338X & $7.94 \pm 0.06$ & $8.28 \pm 0.05$ & $6.22 \pm 0.07$ \\
\hline \multicolumn{5}{|l|}{ cAMP (CRE reporter) } \\
\hline Potency $\left(\mathrm{pIC}_{50} \pm\right.$ S.E.M.) & WT & $6.8 \pm 0.1$ & $8.0 \pm 0.1$ & $6.7 \pm 0.2$ \\
\hline Potency $\left(\mathrm{pIC}_{50} \pm\right.$ S.E.M. $)$ & R334X & $7.0 \pm 0.1$ & $7.9 \pm 0.1$ & $7.3 \pm 0.1$ \\
\hline Potency $\left(\mathrm{pIC}_{50} \pm\right.$ S.E.M.) & S338X & $7.0 \pm 0.1$ & $7.6 \pm 0.1$ & $7.2 \pm 0.1$ \\
\hline CXCL12 inhibition ( $\% \pm$ S.E.M.) & WT & $77 \pm 13$ & $107 \pm 9$ & $71 \pm 15$ \\
\hline CXCL12 inhibition ( $\% \pm$ S.E.M.) & R334X & $84 \pm 10$ & $109 \pm 10$ & $64 \pm 9$ \\
\hline CXCL12 inhibition (\% \pm S.E.M.) & S338X & $78 \pm 10$ & $103 \pm 14$ & $61 \pm 10$ \\
\hline \multicolumn{5}{|l|}{ Ca flux } \\
\hline CXCL12 inhibition (\% \pm S.E.M.) & WT & N.D. & $93 \pm 2$ & $96 \pm 1$ \\
\hline CXCL12 inhibition ( $\% \pm$ S.E.M.) & R334X & N.D. & $70 \pm 9$ & $83 \pm 4$ \\
\hline
\end{tabular}

N.D., not determined. 
Following the evaluation of 10A10 binding characteristics, the CXCR4 nanobodies were functionally characterized in CXCR4 signaling assays. The nanobodies and AMD3100 fully antagonized CXCL12-induced signaling of CXCR4-WT and CXCR4-R334X (Fig. 3A) and CXCR4-S338X (Supplemental Fig. 1C) mutants. However, the nanobodies showed potencies that were up to 100-fold greater than that of AMD3100 (Table 2). We then evaluated the potential of the CXCR4 antagonists to inhibit CXCL12-induced, CXCR4-dependent ERK1/2 activation. Preincubation of CXCR4-WT or CXCR4-WHIM (R334X) expressing cells with saturating concentrations $\left(>50 \times K_{\mathrm{D}}\right)$ of CXCR4 antagonist for a period of 1 hour strongly inhibited the CXCL12induced ERK1/2 activation after 5- or 15-minute treatments (Fig. 3B). CXCR4-mediated signaling via $\mathrm{G} \alpha \alpha_{\mathrm{i}}$ results in reduced levels of cAMP associated with reduced $\mathrm{CRE}$ gene regulation. No differences in potency or efficacy in CXCL12-induced $\mathrm{G} \alpha_{\mathrm{i}}$ activation could be detected between the WT and WHIM mutants (Supplemental Fig. 1D). Inhibition of CXCL12-induced $\mathrm{G} \alpha \alpha_{\mathrm{i}}$ activation by either the nanobodies or AMD3100 resulted in a dose-dependent increase in cAMP levels in cases of either CXCR4-WT or CXCR4R334X (Fig. 3, C and D) and CXCR4-S338X (Supplemental Fig. 1E). In the case of CXCR4-WT, AMD3100 partially inhibited CXCL12-induced CRE-Luc activation, while the bivalent nanobody completely inhibited CXCL12-induced $\mathrm{G} \alpha$ i activation with increased potency (Table 2). None of the antagonists showed differences in potencies or efficacies between the CXCR4-WT and WHIM mutants.

After these initial pharmacological analyses in HEK293T cells, the CXCR4 nanobodies were evaluated in more clinically relevant cell lines and assays. Previously, McDermott et al. (2011b) generated CXCR4-WT and CXCR4-R334X overexpressing K652 cell lines, which are of myleoid leukemic origin. Here, we used these cells to study real-time calcium flux responses upon CXCL12 stimulation. First, we analyzed the CXCL12 response in parental K562 cells or K562 cells expressing CXCR4-WT or CXCR4-R334X. The CXCR4-expressing cells clearly displayed an increase in intracellular calcium release upon CXCL12 stimulation, which was not detected in the parental K562 cells (Fig. 4A). Moreover, this CXCL12induced calcium response could be fully inhibited with either AMD3100 $(10 \mu \mathrm{M})$ or $10 \mathrm{~A} 10-10 \mathrm{~A} 10(100 \mathrm{nM})$ in the case of CXCR4-WT and almost fully in case of the CXCR4-R334X mutant (Fig. 4B; Table 2).

WHIM syndrome has been linked to HPV-associated malignancies (Chow et al., 2010; Beaussant Cohen et al., 2012). Furthermore, HPV18-immortalized human keratinocytes display autocrine CXCL12/CXCR4 signaling that enhances cell migration (Chow et al., 2010). Therefore, we assessed the effect of our CXCR4 nanobodies on migration of these HPV18immortalized human keratinocyte cells in a wound-healing assay (Fig. 4, C and D). Without treatment, this wound was closed entirely after 16 hours of culture. The bivalent nanobodies significantly inhibited this wound healing up to $60 \%$ in a dose-dependent manner (Fig. 4D). In contrast, AMD3100 $(25 \mu \mathrm{M})$ was only able to reach $26 \%$ of wound healing. To summarize, these data indicate that the CXCR4 nanobodies effectively antagonize CXCL12 function, with overall superior pharmacological characteristics compared with AMD3100.

\section{Discussion}

In this study, we pharmacologically characterized CXCR4targeting nanobodies on CXCR4-WT and WHIM-related CXCR4 mutants. Different WHIM mutants, predominantly varying in the length of their C-terminal tail, have been described that display similar biologic phenotypes (Lagane et al., 2008; McCormick et al., 2009; McDermott et al., 2011b; Kallikourdis et al., 2013). The most common WHIM mutants
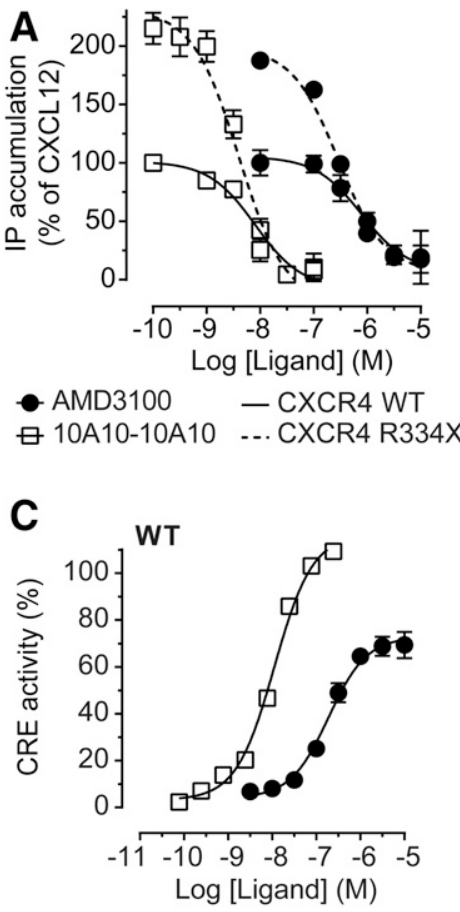

- AMD3100 छ10A10-10A10

\begin{tabular}{|c|c|c|c|}
\hline $\begin{array}{l}\text { WT } \\
\quad \text { Untr. }\end{array}$ & AMD3100 & $\begin{array}{l}10 \mathrm{~A} 10- \\
10 \mathrm{~A} 10 \\
\end{array}$ & \\
\hline $\begin{array}{lll}0 & 5 & 15 \\
\end{array}$ & $\begin{array}{lll}0 & 5 & 15\end{array}$ & $\begin{array}{lll}0 & 5 & 15 \\
\end{array}$ & CXCL12 (min) \\
\hline$-\approx=$ & $\approx=-$ & $-\leq-\leq$ & pERK1/2 \\
\hline$\approx=\approx$ & $\approx \approx \approx=$ & $\approx=2$ & ERK1/2 \\
\hline R334X & & 10A10- & \\
\hline Untr. & AMD3100 & $10 \mathrm{~A} 10$ & \\
\hline $\begin{array}{lll}0 & 5 & 15 \\
\end{array}$ & $\begin{array}{lll}0 & 5 & 15\end{array}$ & $\begin{array}{lll}0 & 5 & 15 \\
\end{array}$ & CXCL12 (min) \\
\hline$-\approx \approx$ & $-3<$ & $-2-2$ & pERK1/2 \\
\hline$\approx \approx \approx$ & $\Leftrightarrow=$ & $\approx \approx \approx \approx$ & ERK1/2 \\
\hline
\end{tabular}

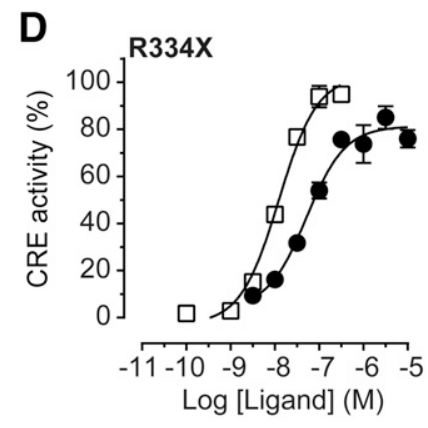

- AMD3100 छ10A10-10A10
Fig. 3. Nanobodies inhibit CXCL12-induced signaling mediated by CXCR4-WT and WHIM mutants. (A) Inhibition of CXCL12-induced ( $5 \mathrm{nM})$ accumulation of $\left[{ }^{3} \mathrm{H}\right]$-inositol phosphates in HEK293T cells expressing CXCR4-WT or WHIM mutant R334X (dashed line) by a concentration range of AMD3100 (solid circles) or 10A1010A10 (open squares). CXCR4-mediated phospholipase C activation was obtained by coexpression with $\mathrm{G} \alpha_{\mathrm{qi} i 5}$. (B) Inhibition of CXCL12-induced $(1 \mathrm{nM})$ phosphorylation of ERK1/2 by AMD3100 $(1 \mu \mathrm{M})$ and 10A10-10A10 $(100 \mathrm{nM})$ in HEK293T expressing CXCR4-WT (top) or WHIM mutant R334X (bottom), as determined by western blot. Total ERK1/2 was stained as loading control. (C and D) Inhibition of CXCL12-induced CRE activation by concentration ranges of AMD3100 (solid circles) or 10A10-10A10 (open squares) in HEK293T cells expressing CXCR4-WT (C) or WHIM mutant R334X. Values are plotted in percentages of maximal effect, where $0 \%$ represents the response to $1 \mathrm{nM}$ of CXCL12 and $100 \%$ represents $1 \mu \mathrm{M}$ of forskolin (D). Plotted are mean and S.E.M. values. 


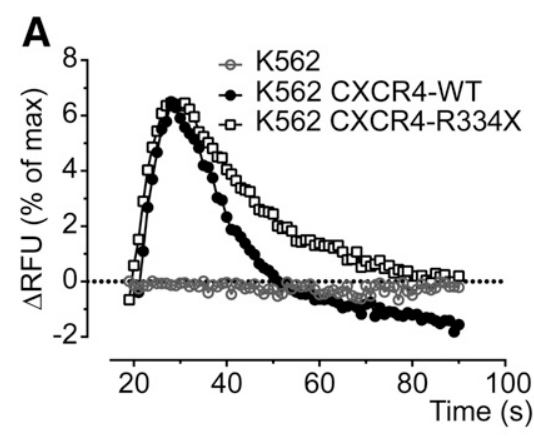

B
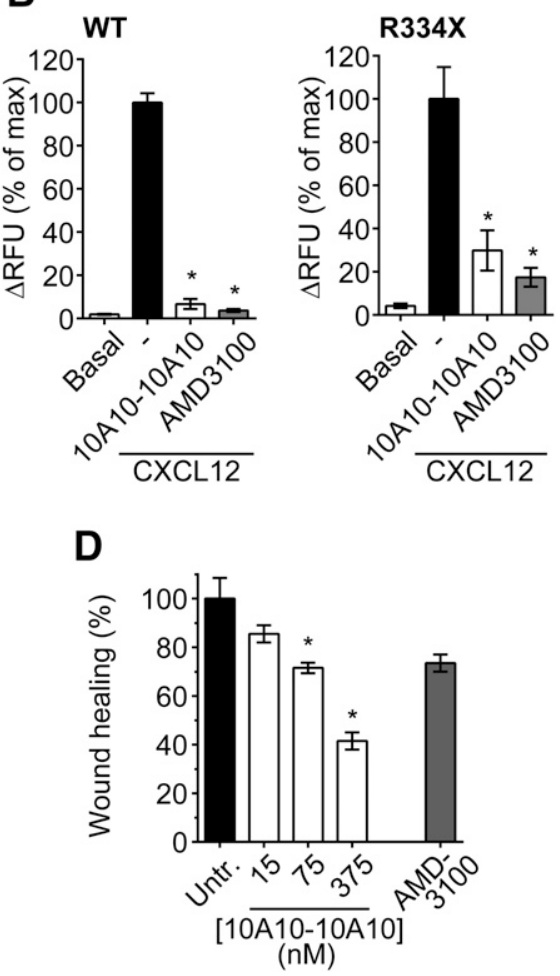

Fig. 4. Nanobody-mediated inhibition of CXCR4 signaling in WHIM-related disease model systems. (A) Realtime calcium flux responses in myleoid leukemic K562 cells (open circles) expressing CXCR4-WT (solid circles) or WHIM mutant R334X (open squares). Cells were treated with CXCL12 (5 nM, black arrow) and intracellular calcium release was monitored by measuring the fluorescence intensity of Fluor-4 NW dye. (B) Inhibition of CXCL12-induced (5 nM) calcium flux in K562 cells expressing CXCR WT (left) or WHIM mutant R334X (right) by nanobody 10A10-10A10 (100 nM) or AMD3100 $(10 \mu \mathrm{M})$. (C and D) Inhibition of wound healing by a concentration range of 10A10-10A10 or AMD3100 $(25 \mu \mathrm{M})$ using HPV18-immortalized human keratinocytes. Wound healing was monitored for 16 hours in the presence of the inhibitors and the degree of wound healing was calculated as the percentage of total gap closure. Plotted are mean and S.E.M. values.
CXCR4-R334X and -S338X were used in our study (Beaussant Cohen et al., 2012). Homologous radioligand displacement showed similar binding affinities of CXCL12 for these WHIM mutants as to CXCR4 WT. However, WHIM mutants showed a 2-fold increase in CXCL12-induced $\mathrm{G} \alpha_{\mathrm{i}}$ response and phosphorylation of ERK1/2 activation was sustained. Furthermore, we observed no differences in cell surface expression, ligand binding, and signaling between CXCR4-R334X and -S338X receptors. These findings are in line with previous reports that described increased and sustained signaling of CXCR4-WHIM mutants (Balabanian et al., 2005; Mueller et al., 2013; Cao et al., 2015). CXCR4 is known to be ubiquitously expressed in several cell types, including HEK293T cells, which may complicate studying the characteristics of CXCR4 mutants. In our signaling assays using HEK293T cells, we did not observe significant CXCL12 responses (Supplementary Fig. 1A) in mock-transfected cells, indicating that the data generated with HEK293T-CXCR4 overexpression models were not compromised by endogenous CXCR4 expression.

In small-scale WHIM syndrome clinical trials, the FDA-approved small-molecule CXCR4 antagonist AMD3100/plerixafor appeared to be relatively safe and effective for WHIM syndrome treatment. We characterized the ability of novel CXCR4-targeting nanobodies, monovalent and bivalent 10A10, to inhibit the WHIM syndrome phenotype. In this study, AMD3100 was used as a benchmark antagonist of CXCL12-induced CXCR4 signaling. Radioligand displacement assays showed that the bivalent CXCR4-specific nanobody 10A10 fully inhibits binding of ${ }^{125}$ I-CXCL12 to human CXCR4. No differences in displacement were observed between CXCR4-WT and WHIM mutants. With potency values that were 10-fold (monovalent nanobody) and 100-fold (bivalent nanobody) greater than that of AMD3100, the CXCR4-targeting nanobodies are superior to AMD3100. The gain in potency observed for the bivalent nanobody is likely due to an increased binding avidity that is obtained by combining two binding affinities in one molecule (Rudnick and Adams, 2009; Vauquelin and Charlton, 2013).

CXCR4 binds to its natural ligand CXCL12 via interactions with the N-terminus and ECL2 of the receptor (Brelot et al., 2000; Cutolo et al., 2017). Within this ECL2, the aspartic acid at position 187 (D187) was previously described to be involved in binding of CXCL12 (Brelot et al., 2000; Jähnichen et al., 2010; Wescott et al., 2016). The D187 residue was also shown to be crucial for binding of the 10A10 CXCR4 nanobody to the receptor. In addition, mutation of the valine at position 196 (V196) caused a 10-fold decrease in affinity. The two previously described, chemokine-competing, CXCR4 nanobodies 238D4 and 238D2 required either D187 (nanobody 238D4) or V196 (nanobody 238D2) (Jähnichen et al., 2010). The overlap in ECL2 residues involved in binding of either CXCL12 nanobody-the previously described nanobodies or our new 10A10 nanobody-correlates well with the ability of these nanobodies to displace CXCL12 from CXCR4.

The potential of the CXCR4 nanobodies to antagonize CXCL12-dependent signaling was evaluated in multiple functional assays that reflect divergent CXCR4 signaling routes or differences in the extent of signal amplification (second messenger levels versus gene regulation). In general, each antagonist was equipotent and equieffective in antagonizing either the CXCR4-WT or CXCR4-WHIM receptors. The nanobodies showed higher potencies in inhibiting CXCL12-induced $\mathrm{G} \alpha_{\mathrm{i}}$ activation compared with $\mathrm{AMD} 3100$, with $\mathrm{IC}_{50}$ values that reflect their binding affinities. Also, in the cAMP reporter assay, the bivalent nanobody was significantly more potent than AMD3100. After these initial signaling studies in HEK293T cells, the nanobodies were further validated in clinically more relevant WHIM-related cell lines. In leukemic K562 cells, the CXCL12-induced calcium 
flux, mediated by either CXCR4-WT or CXCR4-R334X, was inhibited by both the nanobodies and AMD3100. WHIM syndrome is often clinically characterized by HPV-associated warts and carcinogenesis. Such manifestations might be directly related to aberrant CXCR4-WHIM signaling, as suggested by the interplay between the CXCL12 signaling axis and the HPV life cycle (Chow et al., 2010; Meuris et al., 2016). Such interplay is notably manifested by the CXCL12 dependency of HPV-immortalized keratinocyte migration, which can be measured in a wound-healing assay (Chow et al., 2010). We found that the nanobody dose dependently inhibited the wound healing in HPV-immortalized keratinocytes up to $61 \%$, whereas AMD3100 inhibited only $26 \%$ of the wound. Taken together, our functional experiments demonstrate that these new CXCR4 nanobodies effectively inhibit CXCL12-dependent CXCR4 signaling with potencies that are superior to that of AMD3100.

Because of the small size and modular structure of nanobodies, multivalent nanobody constructs are easily generated. Therefore, to extend the half-life of the nanobodies in blood circulation, target-specific nanobodies are often coupled to nanobodies directed against human or murine albumin (Roovers et al., 2007; Tijink et al., 2008). This half-life extension can increase the half-life of the nanobodies in blood up to several days (Tijink et al., 2008). For example, in clinical tests, interleukin 6 (IL6) receptor nanobodies that have been modified accordingly showed serum half-life of several weeks and therapeutic outcome upon weekly administration (Van Roy et al., 2015). In contrast, AMD3100 is associated with poor pharmacokinetics (blood half-life of only a few hours), forcing its administration to WHIM patients to twice a day (Hendrix et al., 2000; McDermott et al., 2014). Half-life extended variants of CXCR7-specific nanobodies have been described previously (Maussang et al., 2013); similar modification of the CXCR4 nanobodies from this study would render them as potent alternatives for treatment of CXCR4related diseases.

In recent years the nanobody platform has been gaining ground in $\mathrm{G}$ protein-coupled receptor research as therapeutics, diagnostics, and research tools (Mujić-Delić et al., 2014; Manglik et al., 2017). Being stable proteins, nanobodies can be readily tagged with fluorescent probes, radiolabels, or epitope tags, and thus can be used for CXCR4 detection, imaging, and diagnostic purposes (e.g., ELISA, immunohistochemistry, and immunofluorescence) or as crystallization chaperones (MujićDelić et al., 2014; Manglik et al., 2017). Being specific for human CXCR4 allows for detection of hCXCR4-expressing cells in human xenografts in animal experiments or detection of CXCR4 in immunohistochemistry on patient samples. However, future testing of nanobodies in an in vivo WHIM model, such as the Cxcr4 $4^{+/ \text {mutant(1013) }}$ model (the WHIM syndrome-associated CXCR4-S338X mutation) (Balabanian et al., 2012), would require mouse reactive nanobodies. Furthermore, the extracellular localization of the binding epitope of these nanobodies allows them to be used as targeting ligands in noninvasive imaging techniques, such as near-infrared or positron emission tomography imaging or for the delivery of therapeutic payloads to CXCR4expressing cells (Oliveira et al., 2013).

In conclusion, these data illustrate that the bivalent CXCR4targeting nanobody 10A10-10A10 is highly potent in inhibiting CXCL12/CXCR4 signaling. Importantly, their modularity and half-life extension make these nanobodies a promising alternative to AMD3100 for CXCR4-related diseases such as WHIM syndrome and Waldenström's macroglobulinemia.

\section{Acknowledgments}

The authors thank David McDermott and Philip Murphy for the discussions and providing the K562 cell lines. H.F.V., F.B., and M.J.S. are part of the European Union's Horizon 2020 MSCA Programme under Grant Agreement 641833 (ONCORNET).

\section{Authorship Contributions}

Participated in research design: de Wit, Maussang, Cutolo, Bachelerie, Smit.

Conducted experiments: de Wit, Brink, Arsova, Cutolo.

Contributed new reagents or analytic tools: Strubbe.

Performed data analysis: de Wit, Heukers, Brink, Cutolo.

Wrote or contributed to the writing of the manuscript: de Wit, Heukers, Bachelerie, Vischer, Smit.

\section{References}

Al Ustwani O, Kurzrock R, and Wetzler M (2014) Genetics on a WHIM. Br J Haematol 164:15-23.

Bachelerie F (2010) CXCL12/CXCR4-axis dysfunctions: markers of the rare immunodeficiency disorder WHIM syndrome. Dis Markers 29:189-198.

Balabanian K, Brotin E, Biajoux V, Bouchet-Delbos L, Lainey E, Fenneteau O, Bonnet D, Fiette L, Emilie D, and Bachelerie F (2012) Proper desensitization of CXCR4 is required for lymphocyte development and peripheral compartmentalization in mice. Blood 119:5722-5730.

Balabanian K, Lagane B, Pablos JL, Laurent L, Planchenault T, Verola O, Lebbe C, Kerob D, Dupuy A, Hermine O, et al. (2005) WHIM syndromes with different genetic anomalies are accounted for by impaired CXCR4 desensitization to CXCL12. Blood 105:2449-2457.

Ballester LY, Loghavi S, Kanagal-Shamanna R, Barkoh BA, Lin P, Medeiros LJ, Luthra R, and Patel KP (2016) Clinical validation of a CXCR4 mutation screening assay for Waldenstrom macroglobulinemia. Clin Lymphoma Myeloma Leuk 16: 395-403.

Beaussant Cohen S, Fenneteau O, Plouvier E, Rohrlich PS, Daltroff G, Plantier I, Dupuy A, Kerob D, Beaupain B, Bordigoni P, et al. (2012) Description and outcome of a cohort of 8 patients with WHIM syndrome from the French Severe Chronic Neutropenia Registry. Orphanet J Rare Dis 7:71.

Biajoux V, Natt J, Freitas C, Alouche N, Sacquin A, Hemon P, Gaudin F, Fazilleau N, Espéli M, and Balabanian K (2016) Efficient plasma cell differentiation and trafficking require Cxcr4 desensitization. Cell Reports 17:193-205.

Bock I, Dugué F, Loppinet E, Bellanné-Chantelot C, and Bénet B (2014) WHIM syndrome: presumptive diagnosis based on myelokathexis on bone marrow smear. Ann Biol Clin (Paris) 72:111-119.

Brault L, Rovó A, Decker S, Dierks C, Tzankov A, and Schwaller J (2014) CXCR4SERINE339 regulates cellular adhesion, retention and mobilization, and is a marker for poor prognosis in acute myeloid leukemia. Leukemia 28:566-576.

Brelot A, Heveker N, Montes M, and Alizon M (2000) Identification of residues of CXCR4 critical for human immunodeficiency virus coreceptor and chemokine receptor activities. J Biol Chem 275:23736-23744.

Cao Y, Hunter ZR, Liu X, Xu L, Yang G, Chen J, Patterson CJ, Tsakmaklis N, Kanan S, Rodig S, et al. (2015) The WHIM-like CXCR4 ${ }^{\mathrm{S} 338 \mathrm{X}}$ somatic mutation activates AKT and ERK, and promotes resistance to ibrutinib and other agents used in the treatment of Waldenstrom's macroglobulinemia. Leukemia 29:169-176.

Chow KY, Brotin É, Ben Khalifa Y, Carthagena L, Teissier S, Danckaert A, Galzi JL, Arenzana-Seisdedos F, Thierry F, and Bachelerie F (2010) A pivotal role for CXCL12 signaling in HPV-mediated transformation of keratinocytes: clues to understanding HPV-pathogenesis in WHIM syndrome. Cell Host Microbe 8:523-533.

Conklin BR, Farfel Z, Lustig KD, Julius D, and Bourne HR (1993) Substitution of three amino acids switches receptor specificity of $\mathrm{G}_{\mathrm{q}} \alpha$ to that of $\mathrm{G}_{\mathrm{i}} \alpha$. Nature $\mathbf{3 6 3}$ : 274-276.

Cutolo P, Basdevant N, Bernadat G, Bachelerie F, and Ha-Duong T (2017) Interaction of chemokine receptor CXCR4 in monomeric and dimeric state with its endogenous ligand CXCL12: coarse-grained simulations identify differences. J Biomol Struct Dyn 35:399-412.

Dale DC, Bolyard AA, Kelley ML, Westrup EC, Makaryan V, Aprikyan A, Wood B, and Hsu FJ (2011) The CXCR4 antagonist plerixafor is a potential therapy for myelokathexis, WHIM syndrome. Blood 118:4963-4966.

De Clercq E (2003) The bicyclam AMD3100 story. Nat Rev Drug Discov 2:581-587.

de Wit RH, de Munnik SM, Leurs R, Vischer HF, and Smit MJ (2016) Molecular pharmacology of chemokine receptors. Methods Enzymol 570:457-515.

Devine SM, Flomenberg N, Vesole DH, Liesveld J, Weisdorf D, Badel K, Calandra G, and DiPersio JF (2004) Rapid mobilization of CD34+ cells following administration of the CXCR4 antagonist AMD3100 to patients with multiple myeloma and non-Hodgkin's lymphoma. J Clin Oncol 22:1095-1102.

Els Conrath K, Lauwereys M, Wyns L, and Muyldermans S (2001) Camel singledomain antibodies as modular building units in bispecific and bivalent antibody constructs. J Biol Chem 276:7346-7350.

Förster R, Kremmer E, Schubel A, Breitfeld D, Kleinschmidt A, Nerl C, Bernhardt G, and Lipp M (1998) Intracellular and surface expression of the HIV-1 coreceptor CXCR4/fusin on various leukocyte subsets: rapid internalization and recycling upon activation. $J$ Immunol 160:1522-1531.

Freitas C, Wittner M, Nguyen J, Rondeau V, Biajoux V, Aknin ML, Gaudin F, Beaussant-Cohen S, Bertrand Y, Bellanné-Chantelot C, et al. (2017) Lymphoid differentiation of hematopoietic stem cells requires efficient Cxcr4 desensitization. J Exp Med 214:2023-2040. 
Gorlin RJ, Gelb B, Diaz GA, Lofsness KG, Pittelkow MR, and Fenyk JR, Jr (2000) WHIM syndrome, an autosomal dominant disorder: clinical, hematological, and molecular studies. Am J Med Genet 91:368-376.

Gravel S, Malouf C, Boulais PE, Berchiche YA, Oishi S, Fujii N, Leduc R, Sinnett D, and Heveker N (2010) The peptidomimetic CXCR4 antagonist TC14012 recruit $\beta$-arrestin to CXCR7: roles of receptor domains. J Biol Chem 285:37939-37943.

Hendrix CW, Flexner C, MacFarland RT, Giandomenico C, Fuchs EJ, Redpath E, Bridger G, and Henson GW (2000) Pharmacokinetics and safety of AMD-3100, a novel antagonist of the CXCR-4 chemokine receptor, in human volunteers. Antimicrob Agents Chemother 44:1667-1673.

Hernandez PA, Gorlin RJ, Lukens JN, Taniuchi S, Bohinjec J, Francois F, Klotman ME, and Diaz GA (2003) Mutations in the chemokine receptor gene CXCR4 are associated with WHIM syndrome, a combined immunodeficiency disease. Nat Genet 34:70-74.

Hunter ZR, Xu L, Yang G, Zhou Y, Liu X, Cao Y, Manning RJ, Tripsas C, Patterson CJ, Sheehy P, et al. (2014) The genomic landscape of Waldenstrom macroglobulinemia is characterized by highly recurring MYD88 and WHIM-like CXCR4 mutations, and small somatic deletions associated with B-cell lymphomagenesis. Blood 123:1637-1646.

Imashuku S, Miyagawa A, Chiyonobu T, Ishida H, Yoshihara T, Teramura T, Kuriyama K, Imamura T, Hibi S, Morimoto A, et al. (2002) Epstein-Barr virusassociated T-lymphoproliferative disease with hemophagocytic syndrome, followed by fatal intestinal B lymphoma in a young adult female with WHIM syndrome. Warts, hypogammaglobulinemia, infections, and myelokathexis. Ann Hematol 81:470-473.

Jähnichen S, Blanchetot C, Maussang D, Gonzalez-Pajuelo M, Chow KY, Bosch L, De Vrieze S, Serruys B, Ulrichts H, Vandevelde W, et al. (2010) CXCR4 nanobodies (VHH-based single variable domains) potently inhibit chemotaxis and HIV-1 replication and mobilize stem cells. Proc Natl Acad Sci USA 107:20565-20570.

Kallikourdis M, Trovato AE, Anselmi F, Sarukhan A, Roselli G, Tassone L, Badolato R, and Viola A (2013) The CXCR4 mutations in WHIM syndrome impair the stability of the T-cell immunologic synapse. Blood 122:666-673.

Kapoor P, Paludo J, Vallumsetla N, and Greipp PR (2015) Waldenström macroglobulinemia: What a hematologist needs to know. Blood Rev 29:301-319.

Kawai T and Malech HL (2009) WHIM syndrome: congenital immune deficiency disease Curr Opin Hematol 16:20-26.

Lagane B, Chow KY, Balabanian K, Levoye A, Harriague J, Planchenault T, Baleux F, Gunera-Saad N, Arenzana-Seisdedos F, and Bachelerie F (2008) CXCR4 dimerization and $\beta$-arrestin-mediated signaling account for the enhanced chemotaxis to CXCL12 in WHIM syndrome. Blood 112:34-44.

Lee B, Sharron M, Montaner LJ, Weissman D, and Doms RW (1999) Quantification of CD4, CCR5, and CXCR4 levels on lymphocyte subsets, dendritic cells, and differentially conditioned monocyte-derived macrophages. Proc Natl Acad Sci USA 96 $5215-5220$

Liles WC, Broxmeyer HE, Rodger E, Wood B, Hübel K, Cooper S, Hangoc G, Bridger GJ, Henson GW, Calandra G, et al. (2003) Mobilization of hematopoietic progenitor cells in healthy volunteers by AMD3100, a CXCR4 antagonist. Blood 102:2728-2730.

Liu Q, Chen H, Ojode T, Gao X, Anaya-O'Brien S, Turner NA, Ulrick J, DeCastro R, Kelly C, Cardones AR, et al. (2012) WHIM syndrome caused by a single amino acid substitution in the carboxy-tail of chemokine receptor CXCR4. Blood 120:181-189.

Liu Q, Pan C, Lopez L, Gao J, Velez D, Anaya-O'Brien S, Ulrick J, Littel P, Corns JS, Ellenburg DT, et al. (2016) WHIM syndrome caused by Waldenström's macroglobulinemia-associated mutation CXCR4 $4^{\text {L329fs }}$. J Clin Immunol 36:397-405.

Ma Q, Jones D, and Springer TA (1999) The chemokine receptor CXCR4 is required for the retention of B lineage and granulocytic precursors within the bone marrow microenvironment. Immunity 10:463-471.

Manglik A, Kobilka BK, and Steyaert J (2017) Nanobodies to study G protein-coupled receptor structure and function. Annu Rev Pharmacol Toxicol 57:19-37.

Maussang D, Mujić-Delić A, Descamps FJ, Stortelers C, Vanlandschoot P, Stigter-van Walsum M, Vischer HF, van Roy M, Vosjan M, Gonzalez-Pajuelo M, et al. (2013) Llama-derived single variable domains (nanobodies) directed against chemokine receptor CXCR7 reduce head and neck cancer cell growth in vivo. $J$ Biol Chem 288: 29562-29572.

McCormick PJ, Segarra M, Gasperini P, Gulino AV, and Tosato G (2009) Impaired recruitment of Grk6 and $\beta$-arrestin 2 causes delayed internalization and desensitization of a WHIM syndrome-associated CXCR4 mutant receptor. PLoS One 4:e8102.

McDermott DH, Gao JL, Liu Q, Siwicki M, Martens C, Jacobs P, Velez D, Yim E, Bryke CR, Hsu N, et al. (2015) Chromothriptic cure of WHIM syndrome. Cell 160: 686-699.

McDermott DH, Liu Q, Ulrick J, Kwatemaa N, Anaya-O’Brien S, Penzak SR, Filho JO, Priel DA, Kelly C, Garofalo M, et al. (2011a) The CXCR4 antagonist plerixafor corrects panleukopenia in patients with WHIM syndrome. Blood 118:4957-4962.
McDermott DH, Liu Q, Velez D, Lopez L, Anaya-O'Brien S, Ulrick J, Kwatemaa N, Starling J, Fleisher TA, Priel DAL, et al. (2014a) A phase 1 clinical trial of longterm, low-dose treatment of WHIM syndrome with the CXCR4 antagonist plerixafor. Blood 123:2308-2316.

McDermott DH, Lopez J, Deng F, Liu Q, Ojode T, Chen H, Ulrick J, Kwatemaa N, Kelly C, Anaya-O'Brien S, et al. (2011b) AMD3100 is a potent antagonist at $\mathrm{CXCR}^{\mathrm{R} 334 \mathrm{X}}$, hyperfunctional mutant chemokine receptor and cause of WHIM syndrome. J Cell Mol Med 15:2071-2081.

Meuris F, Carthagena L, Jaracz-Ros A, Gaudin F, Cutolo P, Deback C, Xue Y, Thierry F, Doorbar J, and Bachelerie F (2016) The CXCL12/CXCR4 signaling pathway: a new susceptibility factor in human papillomavirus pathogenesis. PLoS Pathog 12: e1006039.

Mueller W, Schütz D, Nagel F, Schulz S, and Stumm R (2013) Hierarchical organization of multi-site phosphorylation at the CXCR4 $\mathrm{C}$ terminus. PLoS One 8 : e64975.

Mujić-Delić A, de Wit RH, Verkaar F, and Smit MJ (2014) GPCR-targeting nanobodies: attractive research tools, diagnostics, and therapeutics. Trends Pharmacol Sci 35:247-255.

Oliveira S, Heukers R, Sornkom J, Kok RJ, and van Bergen en Henegouwen PMP (2013) Targeting tumors with nanobodies for cancer imaging and therapy. $J$ Control Release 172:607-617.

Peyvandi F, Scully M, Kremer Hovinga JA, Cataland S, Knöbl P, Wu H, Artoni A, Westwood JP, Mansouri Taleghani M, Jilma B, et al.; TITAN Investigators (2016 Caplacizumab for acquired thrombotic thrombocytopenic Purpura. $N$ Engl $J \mathrm{Med}$ 374:511-522.

Roccaro AM, Sacco A, Jimenez C, Maiso P, Moschetta M, Mishima Y, Aljawai Y, Sahin I, Kuhne M, Cardarelli P, et al. (2014) C1013G/CXCR4 acts as a driver mutation of tumor progression and modulator of drug resistance in lymphoplasmacytic lymphoma. Blood 123:4120-4131.

Roovers RC, Laeremans T, Huang L, De Taeye S, Verkleij AJ, Revets H, de Haard HJ, and van Bergen en Henegouwen PMP (2007) Efficient inhibition of EGFR signaling and of tumour growth by antagonistic anti-EFGR nanobodies. Cancer Immunol Immunother 56:303-317.

Rudnick SI and Adams GP (2009) Affinity and avidity in antibody-based tumor targeting. Cancer Biother Radiopharm 24:155-161.

Schlaeger EJ and Christensen K (1999) Transient gene expression in mammalian cells grown in serum-free suspension culture. Cytotechnology 30:71-83.

Scozzafava A, Mastrolorenzo A, and Supuran CT (2002) Non-peptidic chemokine receptors antagonists as emerging anti-HIV agents. $J$ Enzyme Inhib Med Chem 17: 69-76.

Steyaert J and Kobilka BK (2011) Nanobody stabilization of G protein-coupled receptor conformational states. Curr Opin Struct Biol 21:567-572.

Tijink BM, Laeremans T, Budde M, Stigter-van Walsum M, Dreier T, de Haard HJ, Leemans CR, and van Dongen GA (2008) Improved tumor targeting of antiepidermal growth factor receptor nanobodies through albumin binding: taking advantage of modular nanobody technology. Mol Cancer Ther 7:2288-2297.

Van Roy M, Ververken C, Beirnaert E, Hoefman S, Kolkman J, Vierboom M, Breedveld E, 't Hart B, Poelmans S, Bontinck L, et al. (2015) The preclinical pharmacology of the high affinity anti-IL-6R Nanobody ${ }^{\circledR}$ ALX-0061 supports its clinical development in rheumatoid arthritis. Arthritis Res Ther 17:135.

Vauquelin G and Charlton SJ (2013) Exploring avidity: understanding the potentia gains in functional affinity and target residence time of bivalent and heterobivalent ligands. Br J Pharmacol 168:1771-1785.

Wang ZX, Berson JF, Zhang TY, Cen YH, Sun Y, Sharron M, Lu ZH, and Peiper SC (1998) CXCR4 sequences involved in coreceptor determination of human immunodeficiency virus type-1 tropism. Unmasking of activity with M-tropic Env glycoproteins. J Biol Chem 273:15007-15015.

Wescott MP, Kufareva I, Paes C, Goodman JR, Thaker Y, Puffer BA, Berdougo E, Rucker JB, Handel TM, and Doranz BJ (2016) Signal transmission through the CXC chemokine receptor 4 (CXCR4) transmembrane helices. Proc Natl Acad Sci USA 113:9928-9933.

Yoshii Y, Kato T, Ono K, Takahashi E, Fujimoto N, Kobayashi S, Kimura F, Nonoyama S, and Satoh T (2015) Primary cutaneous follicle center lymphoma in a patient with WHIM syndrome. J Euro Acad Dermatol Venereol 30:529-530.

Address correspondence to: Martine J. Smit, Division of Medicinal Chemistry, Amsterdam Institute for Molecules, Medicines and Systems, Vrije Universiteit Amsterdam, De Boelelaan 1108, 1081 HZ Amsterdam, The Netherlands. E-mail: mj.smit@vu.nl 